\title{
Social Anxiety Disorder - socio-economic and environmental factors of the silent Disorder
}

\author{
Swati Raje ${ }^{1}$, Aneesh Bhat ${ }^{2}$, Siddhi Pawar ${ }^{3}$, Safa Khan ${ }^{3}$, Aditi Gupta ${ }^{3}$, Andrea Almeida ${ }^{3}$, \\ Gayathri $\mathrm{MN}^{3}$, Alisha Sunil ${ }^{3}$ \\ ${ }^{1}$ Lecturer and Statistician \\ ${ }^{2}$ Associate Professor and Head, Department of Psychiatry \\ ${ }^{3} 3^{\text {rd }}$ MBBS students \\ MIMER Medical College, Talegaon Dabhade, Pune \\ E-mail - bhataneesh@gmail.com \\ Corresponding author - Dr. Aneesh Bhat
}

\begin{abstract}
Introduction: Social Anxiety Disorder of SAD is an anxiety disorder which is the third most prevalent psychiatric disorder. However, it remains to be one of the least understood illnesses. It is often referred to as the silent disorder since very few people approach for treatment as a result of the attached stigma and lack of understanding. A study was conducted to explore the prevalence of SAD in a medical college of Maharashtra.

Methodology: A cross-sectional study was conducted in field practice area of a medical college in Maharashtra. Study population consisted of people from age group 11-25 years. Accordingly, two out of 4 secondary schools were selected at random and data for all the children in the required age group was collected after obtaining permission of the school principal. Online survey forms were made available to college students for collecting data between age group $18-25$ years.

Result: Prevalence of SAD was least (16\%) in the age group 15- 17 years and maximum in 22-25 years of age group. Increase in trend of severity was seen with increasing age group and is statistically significant.

Conclusion: There is a need for more vigorous efforts to recognize and treat SAD at an educational level. There is no doubt that appropriate intervention will be helpful to prevent the disorder or, more realistically, improve the quality of life for those who suffer from SAD.
\end{abstract}

Key Words: SAD, silent disorder, quality of life, educational awareness.

(Paper received $-9^{\text {th }}$ May 2017, Peer review completed $-4^{\text {th }}$ June 2017 , Accepted $-6^{\text {th }}$ June 2017)

\section{INTRODUCTION}

Social anxiety disorder (SAD) is a debilitating and chronic illness characterized by a marked and persistent fear of one or more social or performance situations involving exposure to unfamiliar people or possible scrutiny by others.[1,2] Out of all the anxiety disorders and most of the mental health problems, social anxiety disorder (SAD) is least understood, though it is the third most common psychiatric disorder following depression and alcohol abuse. SAD became an independent diagnosis only with the introduction of DSM-III [3]; and persists to be last in terms of public and professional understanding and awareness. With an attached stigma to begin with, the added factor of lack of awareness deters people suffering from this disorder from treatment; SAD is therefore alternatively also referred to as the "silent disorder". SAD can lead to low levels of confidence, pessimistic approach towards life and thus a failure to grab many upcoming opportunities for them. 
It has been noted that often people diagnosed with SAD will avoid or will not participate in important activities resulting in lower achievements at occupational and academic fronts, have weaker family functioning along with reduction in quality of life, an increase in alcohol and drug misuse and a risk of suicide [4]. Lower levels of productivity and withdrawal from efficient work engagement contribute to national economic liabilities.

Studies have also noted that just over $20 \%$ of people reporting social anxiety disorder as their primary concern, sought treatment, most commonly through general practitioners. This highlights the need to improve the identification, treatment and referral of people with significant social anxiety by general practitioners and other mental health professionals where people with social anxiety typically present [5]. Very few studies are done in developing countries, especially in India. Previous studies have shown the early onset of SAD affecting the age group of 11-25 years. Thus, a study was conducted to find prevalence and causes affecting SAD in young Indian. With this background, a study was designed to assess the burden of SAD in the age group 11-25 years with the following objectives viz. to study prevalence and severity of SAD, to study, socio-economic and environmental factors with respect to SAD and to create awareness about its effect and treatment.

\section{METHODOLOGY}

A cross-sectional study was conducted in field practice area of a medical college in Maharashtra. Study population consisted of people from age group 11-25 years. Considering prevalence of $19.5 \%$ in students of age group 18 years as reported by a study done in India, with Type I error $(\alpha)$ of $5 \%$ and power of test equal to $80 \%$; estimated sample size was 408 . Cluster sampling method was used for collection of data for the age group 11- 16 years. Accordingly, two out of 4 secondary schools were selected at random and data for all the children in the required age group was collected after obtaining permission of the school principal. Online survey forms were made available to college students for collecting data between age group 18 - 25 years. Data was also collected through NGOs working for socially deprived children.

Socioeconomic information was collected using a pre structured questionnaire. Prevalence of social anxiety disorder was studied using Social Phobia Inventory (SPIN) by Jonathan Davidson [6] which is a 17 item scale for assessing each of the symptom domains of SAD. According to this scale score $\leq 50$ is termed as severe between $50-40$ as moderate, $40-20$ as mild and $<20$ is termed as normal.

Data was summarized using percentages. Chi- square test was used to find significant association between socio economic variations and prevalence of SAD.

\section{RESULTS}

The study sample consisted of 266 people in age group 11 to 22 years, 66 people from NGO, and 120 college students selected randomly. Online response surveys were 155 in all hence total sample size was 607. There were 246 males and 348 females. Majority of them (72\%) belonged to nuclear families, while the remaining (28\%) came from joint families. Majority (469; $77.6 \%$ ) of them had siblings and only $22.4 \%$ were single child. Nearly half of them $(46 \%)$ reported to have a negative experience in life. SPIN score of the sample ranged between a score of 0-63. Prevalence of SAD was observed to be $29 \%$ of the population as depicted in Fig 1; while extreme cases were only $1 \%$. The study identified more than $10 \%$ moderate to severe cases. Distribution of social anxiety disorders was further analysed with respect to various socio economic and demographic variables (Table1).

Prevalence of SAD was least (16\%) in the age group 15- 17 years and maximum in 22-25 years of age group. Increase in trend of severity was seen with increasing age group and is statistically significant. Significantly higher prevalence of SAD was observed among people who had no siblings $(37.7 \%)$ as compared to those who had siblings $(26.47 \%)\left(\chi^{2}=4.65, \mathrm{p}<0.03\right)$. 
Prevalence of SAD was more than twice in people who have had negative experiences in their past (42.2\%) as compared to those who did not have such experience (17.7\%). The difference was statistically significant $\left(\chi^{2}=31.07, p<0.0001\right)$. Prevalence of SAD was less in joint families $(26.6 \%)$ as compared to that in nuclear families (30.34\%), However the difference was not statistically significant. Similarly prevalence of SAD did not differ with respect to socio economic class. Prevalence was more in people who do not share anything with their parents (78\%) and friends (72\%).

Table 1: Distribution of severity of SAD with respect to age

\begin{tabular}{|c|c|c|c|c|c|}
\hline \multirow{2}{*}{ Severity } & $\mathbf{1 1 - 1 4}$ years & $\mathbf{1 5 - 1 7}$ years & $\mathbf{1 8 - 2 1}$ years & 22-25 years & \multirow{2}{*}{ Total } \\
\cline { 2 - 5 } & \multicolumn{5}{|c|}{ Age N (\%) } \\
\hline Extreme & 0 & 0 & $4(1.78)$ & $1(3.13)$ & 5 \\
\hline Severe & $5(1.68)$ & $1(2.0)$ & $13(5.78)$ & $2(6.25)$ & 21 \\
\hline Moderate & $13(4.38)$ & $1(2.0)$ & $24(10.67)$ & $7(21.88)$ & 45 \\
\hline Mild & $46(15.49)$ & $6(12.0)$ & $46(20.44)$ & $6(18.75)$ & 104 \\
\hline None & $233(78.45)$ & $42(84.0)$ & $138(61.33)$ & $16(50.0)$ & 429 \\
\hline Total & 297 & 50 & 225 & 32 & 604 \\
\hline
\end{tabular}

\section{DISCUSSION}

Adolescence is a period is characterized by rapid physical growth and sexual maturation, as well as unique emotional and cognitive developments and underlying neurological changes. At the same time, increasing social demands, peer pressure, romantic interests, hormonal changes, and greater independence present a dizzying and sometimes overwhelming array of challenges. The physical, cognitive, and behavioural hallmarks of social anxiety disorder (SAD) often make their first appearance during adolescence.

Social anxiety disorder (SAD) is a debilitating and chronic illness characterized by "a marked and persistent fear of one or more social or performance situations involving exposure to unfamiliar people or possible scrutiny by others" [1-2]. SAD, which was earlier grouped with other phobias, became an independent diagnosis with the print of the Diagnostic and Statistical Manual of Mental Disorders-II, DSM-III [3]. The lifetime prevalence of SAD is between $7 \%$ and $13 \%$ in Western countries [1]. Not much literature and research based data is available for developing countries, especially for India. The high prevalence observed by the current study is comparable to that observed in a similar age group from Kolkata [7] and thus underlines the need or more such studies. Chavira and Stein observed that adolescents seem to have higher rates of SAD than younger age late adolescence, although reports suggest it can begin as early as 7 or 8 years of age [9]. As against previous findings, findings of the present study report least prevalence of SAD among adolescents. Our findings are similar to what was reported by a study from Goa [8] which attributed the cause of this low prevalence to strong family support.

Though the exact causes of SAD are still being explored, Schmidt et al., 2005, have linked biological, psychological and environmental factors to a diathesis-stress paradigm that may represent the etiology of this anxiety disorder [10]. Studies describe four distinct areas of contribution to the development of SAD, including genetic and temperament factors, cognitive aspects, parent child interactions and adverse environments, together added to societal and cultural influences. Marked prevalence of SAD is seen in children in joint families, which could be as a result of a conservative environment and lack of privacy [3]. The contradictory findings, though not statistically significant reported in the present study may be attributed to difference in the environment of joint families in developed countries and that in India.

Little research has been conducted on the part that siblings play in the development of SAD. Significantly high prevalence of SAD amongst those who did not have siblings indicates that the role of having a sibling might be instrumental for reducing emotional burden which in turn is conducive in reducing the 
prevalence of anxiety disorder. The negative experiences in life are known to be associated with psychiatric morbidity. These negative experiences may be inclusive of pre and perinatal adverse life conditions or later. Further, while identifying self-perceived adverse events and psychiatric disorders from the previous year, Tiet found that groups of psychiatric disorders were more closely associated with some adverse life events than with others [11]. Although there has yet to be a causal association established, the current research does point to and aid in developing possible interventions that could alter the developmental course of SAD [9]. In accordance with this, our study points out a significant, high prevalence of SAD among people having past negative experience in past.

Socioeconomic status (SES) is discussed as a potential risk factor in minimal exploration. The relative effect of SES in developed as opposed to developing countries shows interesting differences. In developed countries, research suggests SES may or may not be associated with other psychopathology, and it is conceivable that poverty could be either a cause or the result of psychopathology. This potentially reciprocal relation needs further elucidation.

Bridget and others have observed that having low income significantly increased risk of SAD in adults of United States [12]. No such associations were noted in present study. Reports consistently place females as having higher rates of SAD than males with a ratio of approximately 3:2 [3,13]. However, there was no difference in prevalence of SAD with respect to gender in the present study. As SAD is a preventable disease [14], early diagnosis in vulnerable population can help in reducing its burden, thereby providing a quality of life especially to the young population.

\section{CONCLUSION}

Despite the limitations in the study, the research points to a multi-faceted environmental risk factors to social anxiety disorder. High prevalence of this hidden disease emphasizes the need for early detection of the problem. It further demonstrates the need for more vigorous efforts to recognize and treat SAD at educational level. There is no doubt that appropriate intervention will be helpful to prevent the disorder or, more realistically, improve the quality of life for those who suffer from SAD. The limitation of the study was that clinical confirmation of presence of SAD was beyond the scope of the study.

\section{REFERENCES}

1. Furmark T. Social phobia: overview of community surveys. Acta Psychiatr Scand 2002;105:84-93.

2. Schneier FR. Social anxiety disorder. New Eng J Med 2006;355:1029-36.

3. Hidalgo RB, Barnett SD, Davidson JRT. Social anxiety disorder inreview: two decades of progress. Int J Neuropsychopharmacol 2004;4:279-98.

4. Baldwin DS, Buis C. Burden of social anxiety disorder. In: Bandelow B, Stein DJ (eds): Social Anxiety Disorder. New York: Marcel Dekker ; 2004

5. Crome E, Grove R, Baillie AJ, Sunderland M, Teesson M, Slade T. DSM-IV and DSM-5 social anxiety disorder in the Australian community. Austr NZ J Psychiatry 2015;49(3):227-35.

6. Connor KM, Davidson JR, Churchill LE, Sherwood A, Weisler RH, FOA E. Psychometric properties of the social phobia inventory (SPIN). Br J Psychiatry 2000;176(4):379-86.

7. Deb S, Chatterjee P, Walsh K. Anxiety among High School Students in India: Comparisons across Gender, School Type, Social Strata and Perceptions of Quality Time with Parents. Austr J Educ Dev Psychol 2010;10:18-31.

8. Pillai A, Patel V, Cardozo P, Goodman R, Weiss HA, Andrew G. Non-traditional lifestyles and prevalence of mental disorders in adolescents in Goa, India. Br J Psychiatry 2008;192(1):45-51.

9. Stein MB, Fuetsch M, Müller N, Höfler M, Lieb R, Wittchen HU. Social anxiety disorder and the risk of depression: a prospective community study of adolescents and young adults. Arch Gen Psychiatry 2001;58(3):251-6.

10. Schmidt LA, Polak CP, Spooner AL. Biological and environmental contributions to childhood shyness: a diathesis-stress model. In: Crozier WR, Alden LE (eds): The essential handbook of social anxiety for clinicians. Chichester, UK: John Wiley and Sons; 2005.

11. Tiet QQ, Bird HR, Hoven CW, Moore R, Wu P, Wicks J, Jensen PS, Goodman S, Cohen P. Relationship between specific adverse life events and psychiatric disorders. J Abnorm Child Psychol 2001;29(2):153-64. 
12. Grant BF, Hasin DS, Blanco C, Stinson FS, Chou SP, Goldstein RB, Dawson DA, Smith S, Saha TD, Huang B. The epidemiology of social anxiety disorder in the United States: results from the National Epidemiologic Survey on Alcohol and Related Conditions. J Clin Psychiatry 2005;66(11):135-61

13. Rapee RM, Spence SH. The etiology of social phobia: Empirical evidence and an initial model. Clin Psychol Rev 2004;24(7):737-67.

14. Weinstock LS. Gender differences in the presentation and management of social anxiety disorder. J Clin Psychiatry 1999;60:9-13.

15. Chhabra V, Bhatia MS, Gupta S, Kumar P, Shrivastava S. Prevalence of social phobia in school going adolescents in an urban area. Delhi Psychiatry Journal 2009;12(1):18-25.

16. Iverach L, Rapee RM. Social anxiety disorder and stuttering: Current status and future directions. J Fluency Disord 2014;40:69-82.

Acknowledgements - Authors would like to acknowledge the efforts of Sarah Khan and Jeffy Methew in collection of data.

Source of Funding - Nil

Conflict of Interest - Nil 